\title{
CONTRASTES E CONEXÕES ENTRE O IMPÉRIO OTOMANO E O IMPÉRIO DO BRASIL, NA LEITURA DE MONIQUE SOCHACZEWSKI
}

\author{
Daniel de Oliveira Cunha ${ }^{1}$
}

MONIQUE SOCHACZEWSKI

Do Rio de Janeiro a Istambul: Contrastes e conexões

entre o Brasil e o Império Otomano (1850-1919)

Brasília: Fundação Alexandre de Gusmão, 2017

331 páginas

Estudo pioneiro e inovador baseado em sua tese de doutorado, defendida na Fundação Getúlio Vargas em 2012, o livro da historiadora brasileira Monique Sochaczewski, publicado pela Fundação Alexandre de Gusmão (FUNAG) em 2017, é uma investigação sobre os contrastes e as relações bilaterais entre o Império Otomano e o Império do Brasil, duas "entidades políticas" que se enquadram no que ela define como "impérios periféricos", e aproximados sob a mediação dos Estados europeus. Com estilo sóbrio e detalhista, a autora realizou exaustivo levantamento de material documental e imagético, tendo recorrido a acervos públicos do Brasil, da Turquia e do Reino Unido, entre outros países. Este é um dos poucos e mais profundos estudos comparativos entre as duas civilizações, embora a autora recuse o termo "comparativo" (como se verá abaixo), a despeito da periodização circunscrita às respectivas civilizações, particularmente na conjuntura em que o Império do Brasil se consolidou e até ampliou seu território, ao mesmo tempo em que - eis uma das diferenças mais marcantes - o Império Otomano foi perdendo gradativamente suas possessões, até ser sucedido pela (territorialmente muito menor) República Turca, em 1923.

A obra é dividida em cinco capítulos, agrupados em três partes, além da Introdução. Na Primeira Parte (Capítulo 1), gira em torno do conceito de "império periférico", articulado a uma "sociedade internacional de cunho europeu e em vias de expansão global" (p. 25). A Segunda Parte (Capítulos 2 e 3) trata dos "contrastes" (respectivamente, entre inserções no mundo e entre as duas capitais imperiais). Na Terceira Parte (Capítulos 4 e 5), são reconstruídas as "conexões" (respectivamente, as político-econômicas e as que se referem às políticas brasileiras de imigração).

1 Graduado em Ciências Sociais (FFLCH-USP); mestre em Direito (FD-USP). Link para o Currículo Lattes: http://lattes.cnpq.br/3258010347088636. ORCID ID: 0000-0003-2262-4255. E-mail: oliveiracunha@ hotmail.com. 
A obra ainda contém um anexo iconográfico com 32 imagens, algumas das quais são descritas ao longo dos capítulos.

Sochaczewski assinala, na sucinta Introdução, sua preferência pela ideia de "contrastes", e assinala sua recusa pela "pretensão" a uma "comparação sistemática" entre os dois impérios (p. 27). A taxativa observação é compreensível até certo ponto, pois ela dá a entender que optou por um estilo de escrita e de análise mais fluido, sem o ônus de encaixar sua análise histórica a justificativas teóricas rígidas e à validação de grandes teorias. Além disso, suas principais referências teóricas (a Escola Inglesa e os teóricos da comunicação não verbal na política internacional) costumam ser apontadas em outros lugares como contribuições "ecléticas" à disciplina de Relações Internacionais, o que não necessariamente é uma qualificação pejorativa. Em todo caso, a obra não deixa de ser um estudo comparativo por excelência, metodologicamente próximo aos estudos historiográficos que realçam o "contraste de contextos" (termo de Theda Skocpol e Margaret Somers, referências em Sociologia Histórica Comparativa), isto é, que explicitam as peculiaridades dos casos comparados com base não em generalizações em busca de postulados universais, mas no recurso a tipos ideais (e "império periférico", termo forjado por Sochaczewski, pode ser caracterizado como tipo ideal).

O Capítulo 1 corresponde à apresentação do arcabouço teórico utilizado pela autora, que segue o programa de pesquisa da Escola Inglesa de Relações Internacionais, centrado no conceito de "sociedade internacional", embora ela aponte certo eurocentrismo no pensamento de Hedley Bull (posteriormente corrigido por outros de seus expoentes, como Adam Watson). Leitora crítica que parte de um ponto de vista exterior às regiões "centrais" do planeta (ou seja, oriunda do antigamente chamado Terceiro Mundo), a autora procura preencher essas insuficiências com um empréstimo conceitual pontual, qual seja, o termo "periferia", por ela retrabalhado como "império periférico". A questão principal é mostrar como dois entre os vários impérios periféricos negociaram sua adesão a uma sociedade internacional "em expansão" a partir da Europa e de seus projetos expansionistas e, ao mesmo tempo, conquistaram o reconhecimento com base no princípio da igualdade soberana.

Adentrando os "Contrastes" (Parte II), o Capítulo 2 é dedicado a algumas agendas e compromissos paralelos de política externa: a institucionalização dos respectivos aparatos diplomáticos em conformidade com o padrão geral da "sociedade internacional" e a obrigação de cumprimento dos tratados, mesmo que impostos de modo ostensivo pela potência hegemônica (a Grã-Bretanha), particularmente os compromissos assumidos com a abolição da escravidão (não só o modelo escravocrata brasileiro, mas também o escravismo em contexto islâmico) e o respeito aos direitos das minorias cristãs (no caso otomano). Ainda no tocante às respectivas agendas externas, é traçado um paralelo entre a "busca por alternativas" (ou ao menos "complementos"; p. 177) em termos bilaterais (especialmente em relação aos Estados Unidos, no caso brasileiro, ou em relação à Alemanha, no caso otomano) e entre as objeções feitas pelos dois "impérios periféricos" a certos temas da agenda multilateral (insistência brasileira no princípio da igualdade soberana, e advertência otomana à "civilização europeia" quanto ao respeito pelos fundamentos, instituições, símbolos e devotos do Islã).

Se os dois impérios não fazem parte integral da "civilização europeia", por pertencerem a outras regiões geográficas, devem ao menos se apresentar como sociedades 
"civilizadas" perante as principais potências européias e as "alternativas" a elas, para que sejam aceitos como membros plenos da sociedade internacional. Para mostrar como essa dupla negociação ocorreu, Sochaczewski recorre à emergente disciplina das pesquisas sobre a "comunicação não verbal da diplomacia" (p. 109), que centram o foco nos elementos simbólicos, rituais, cerimoniais, retóricos e literários, em síntese, nos "sinais intrínsecos" da prática diplomática. Algumas ilustrações dessa manifestação de capital simbólico são as viagens de D. Pedro II à Europa e ao Egito (1871-1872), e mais adiante à América do Norte e ao Oriente Próximo (1876-1877), bem como a do sultão Abdul Aziz à Europa (1867). Outras ainda são o envio de representações nas exposições universais, como a de Londres de 1862, em que o Brasil participou pela primeira vez, e a de Paris de 1867, a primeira que contou com a presença otomana. Nos termos da "diplomacia não verbal", esses périplos estão entre os melhores exemplos de "rituais de autocongratulação" (p. 120). Uma das impressões deixadas após a leitura desse capítulo é a de que o imperador brasileiro foi mais bem-sucedido ao melhorar a reputação de seu país que o congênere otomano (a despeito do execrável modelo escravocrata brasileiro). A principal razão para tanto foi de ordem religiosa, uma vez que o sultão era também o califa, o líder espiritual de confissão rival do cristianismo, temida e odiada na Europa desde a época das Cruzadas.

O Capítulo 3 introduz a leitura sobre dois outros símbolos de poder e de prestígio, as capitais imperiais, "palcos" de grandes projetos de modernização urbanística e arquitetônica, "cartões postais" de sociedades aspirantes ao posto de membros plenos de uma sociedade internacional eurocêntrica. Ao buscarem "consolidar sua soberania interna e externamente" (p. 157), as capitais eram, nas palavras da autora, "vitrines" dispostas para o mundo exterior e "escolas" impostas para o interior daquelas entidades políticas em processo de centralização político-administrativa e de nacionalização, no sentido de convergência para a formação de Estados nacionais.

Ao deixarem de ser "vedadas ao olhar europeu", a partir da inviabilização do pacto colonial na América Portuguesa e da discriminação contra os infiéis cristãos na sede do Califado, ambas as cidades puderam ser retratadas com maior riqueza de detalhes. Dois artistas visuais e cenógrafos de "olhar mais atento" sobre as capitais em questão, cada qual autor de uma "Viagem Pitoresca" com "larga divulgação na Europa", são destacados: Antoine-Ignace Melling, segundo Orhan Pamuk, "europeu autêntico" (sic) que teve o gênio de se tornar também um "legítimo istanbullu" (p. 154-6); e Jean-Baptiste Debret, que inaugurou, de acordo com José Murilo de Carvalho, a "história da vida privada em imagens" no Brasil, além de ter sido, para Sochaczewski, uma espécie de biógrafo do país em formação (p. 157-9). Mas essas representações foram apenas "prólogos" das estratégias adotadas mais tarde pelos governantes brasileiros e otomanos, com a ampliação do rol de "instrumentos na busca por inserção internacional” (p. 152).

Introduzindo a Parte III ("Conexões"), o Capítulo 4 apresenta alguns personagens históricos talvez injustamente pouco conhecidos. Um deles é o navegador otomano Piri Reis, com seu conhecimento profundo sobre as navegações de Cristóvão Colombo e as expedições portuguesas inclusive no continente americano e nos Mares do Sul, como revelam os mapas de sua autoria, hoje apenas parcialmente conhecidos. Apesar de seus muitos serviços prestados a sucessivos sultões, Piri, malogrado em sua tentativa de retomar o estreito de Hormuz dos portugueses, teve destino trágico, ao ser decapitado a mando de Suleiman I, em 1554. Do lado sul-americano, outro personagem inusitado na história dos "contatos intraperiféricos" em questão é um dos mais importantes "libertadores da 
América", o venezuelano Francisco de Miranda². Tendo vivido em Constantinopla ainda como observador militar a serviço do Império Espanhol, Miranda desenvolveu um ponto de vista contrário ao da maioria dos preconceituosos viajantes europeus que cruzaram o Bósforo, ao elogiar diversos aspectos da sociedade otomana como um todo, inclusive o imperador, com seu instinto de "responsabilidade pública", que para ele destoava do desprezo que os congêneres ocidentais dispensavam a seus próprios súditos.

Algumas páginas são dedicadas aos momentos imediatamente anteriores e posteriores à assinatura do Tratado de Amizade, Comércio e Navegação entre o Brasil e o Império Otomano, assinado em Londres, em 5 de fevereiro de 1858. Surgem, nesse contexto, diversos outros personagens menos conhecidos de ambas as partes que atuaram, com zelo e "boa vontade", como representantes ou intermediários dos respectivos meios diplomáticos, entre os quais os sempre elogiados dragomanos (intermediários diplomáticos cristãos) Andreas Papolani e Antonio de Summerer, bem como o experiente diplomata brasileiro Antonio Alves Machado de Andrade Carvalho, o por vezes dificultoso embaixador otomano em Londres, (Constantino) Musurus Bey, e os napolitanos da família Debanné, que trabalharam como representantes consulares para sucessivos governos brasileiros, mesmo após o fim da monarquia.

Não surpreende que o motivo principal desse primeiro estabelecimento de relações formais tenha sido o café brasileiro, já então comercializado em grande volume nas diversas províncias do Império Otomano, porém, predominantemente por intermédio de comerciantes europeus. 0 principal interesse brasileiro deveu-se, portanto, ao comércio direto do principal produto responsável pela riqueza nacional, e, tanto melhor, de outros produtos importantes da pauta exportadora, como açúcar e couro. No entanto, em razão das muitas dificuldades de intercâmbio que se interpuseram, essas primeiras conexões se traduziram em uma ligação frouxa e hesitante entre os dois impérios, não tendo alcançado nem mesmo as "intenções iniciais de maior interação comercial” (p. 204).

A penúltima sessão do quarto capítulo é dedicada ao autor de um dos mais importantes relatos da chamada "literatura de viagem" no Brasil, a saber, o imã árabe otomano Al-Baghdadi. Tripulante de um vapor da Marinha otomana a caminho dos domínios imperiais com saída para o Índico, Al-Baghdadi teve a oportunidade de conhecer algumas cidades litorâneas brasileiras na década de 1860, devido a uma escala para ajustes técnicos no navio. Surpreendido com a presença de milhares de escravos muçulmanos no Rio de Janeiro, na Bahia e em Pernambuco, oriundos da África Ocidental, decidiu se estabelecer no Brasil por três anos, com o propósito de "instruir" e "retificar a conduta" dos fiéis islâmicos, dada sua aparente "ignorância" sobre "rituais e afins" (p. 205-8). Foram essas, assinala a autora, as primeiras impressões diretas de um otomano na América do Sul, do mesmo modo como as de Francisco de Miranda haviam sido as primeiras de um sul-americano nos domínios otomanos.

Na direção oposta, também houve brasileiros "de destaque" que visitaram os domínios otomanos na segunda metade do século XIX, como o engenheiro mineiro Christiano Benedito Ottoni, atraído pelas obras do Canal de Suez e da malha ferroviária em expansão no Egito (p. 209). Mas o viajante mais ilustre foi o próprio imperador.

Suas duas viagens à região (ao menos duas ao Egito) são tratadas na última sessão do ca-

\footnotetext{
2 Também rememorado no Brasil, especialmente na cidade de São Paulo, por ter uma estátua em sua homenagem na Avenida Paulista.
} 
pítulo. D. Pedro II tinha especial interesse pelo Egito Antigo, pela egiptologia e até mesmo pelo significado dos hieróglifos (p. 162). É sabido que falava seis idiomas e estudou outros a fundo. Ainda em seu reinado, estudou árabe, hebraico, persa, sânscrito e turco com especialistas, como o barão austríaco Gustave Schreiner (p. 213); durante seu exílio em Paris, às vésperas de sua morte, manteve as aulas de línguas do Oriente Médio com o orientalista alemão Christian Friedrich Seybold (p. 256).

Apesar de os dois périplos terem sido descritos à época como discretas "viagens em incógnito", Sochaczewski discorda da interpretação segundo a qual tenham sido meros "tours de distração". Para ela, devido aos encontros protocolares e ao capital simbólico envolvido, representaram também uma modalidade de "diplomacia de chefe de estado" (p. 125). Mesmo assim, ela conclui que o imperador foi um "orientalista” (p. 220), não no sentido do político engajado, dado por Edward Said, mas no sentido usado por Robert Irwin, o do "diletante", curioso, porém politicamente desinteressado.

A imigração de súditos otomanos de diversas origens para o Brasil é o tema do Capítulo 5. Para além das relações formais entre as duas entidades políticas, mesmo que "tênues", os primeiros fluxos migratórios de "turcos" (súditos do Império Otomano) para as Américas a partir da década de 1870 ocorreram em grande parte por financiamento próprio entre indivíduos e famílias. É sugestivo que os primeiros árabes oriundos da "Grande Síria" tenham vindo por conta própria, pois o Estado brasileiro manifestava preferência por imigrantes europeus e norte-americanos, por estes serem considerados mais "civilizados". Preconceitos oficiais à parte, a autora mostra como última viagem de Pedro II ao Oriente Próximo, assim como seu discreto apoio financeiro para a criação de estabelecimentos religiosos cristãos e educacionais na região, parecem ter servido como incentivo para que famílias de cristãos árabes e de armênios se interessassem pelo Brasil como opção de refúgio. Em todo caso, não há evidências documentais que comprovem algum interesse oficial do Estado imperial em promover o Brasil como destino potencial para essas comunidades (p. 235).

As primeiras famílias gregas recebem tratamento talvez demasiado sucinto pela autora, em termos de origens geográficas e sociais, bem como de motivações para seu deslocamento para o Brasil. Aparentemente de melhor condição social, se comparadas a outros grupos, vieram tanto da Grécia quanto da Anatólia e se estabeleceram em diversos estados brasileiros.

Já os primeiros armênios que se estabeleceram no Brasil se deslocaram voluntariamente, ainda antes das migrações forçadas causadas pelos grandes massacres que culminaram nos controversos episódios de 1915. Entre os pioneiros estava o engenheiro ferroviário Mihan Latif, nascido em Constantinopla. Convidado pessoalmente por Pedro II a se estabelecer no Brasil, residiu no país em duas ocasiões, tendo se casado com brasileira e participado da construção de estradas de ferro em Minas Gerais, bem como de reformas urbanísticas no Rio de Janeiro (p. 247).

Por fim, o fluxo de súditos judeus do Império Otomano para o Brasil foi também causada não tanto por pressões humanitárias e querelas diplomáticas entre europeus e otomanos (quando comparada com a dos armênios), mas mais diretamente pela ascensão do nacionalismo turco e o consequente fim da "vida comunitária independente" nos millets. Como o processo de "turquificação" implicava na obrigatoriedade do serviço militar, o custo de oportunidade da saída caiu drasticamente, principalmente durante o regime 
dos Jovens Turcos. Depoimentos valiosos de imigrantes judeus no Brasil mostram que a tolerância em relação aos judeus era maior quando comparada com aquela dispensada a outros grupos (p. 253).

Entre todos esses grupos que compunham a "colônia otomana", os árabes foram os que mais sofreram com o processo de inclusão e adaptação social, tanto no Brasil como em outras localidades da América do Sul (particularmente a Argentina). Devido ao grande número de crimes e mesmo de assassinatos cometidos contra os mascates no interior desses países, o Império Otomano, em seus últimos anos de existência, acabou por estreitar relações diplomáticas com esses países, oficialmente com o intuito de defender os interesses e a vida de seus súditos. Entretanto, o objetivo maior parece ter sido o de barrar a imigração otomana e, assim, evitar que potenciais emigrantes fugissem ao crescentemente demandado alistamento obrigatório no exército otomano (p. 260).

Como balanço geral do livro, é de se destacar que a sensibilidade da autora no tratamento dos contrastes e das conexões entre as duas entidades políticas vai além dos aspectos das relações diplomáticas formais, ultrapassando até mesmo o limiar do que ela caracteriza como "diplomacia não verbal" e "informal", ou extra-oficial, já que ela também apresenta o aspecto societário da aproximação entre as duas civilizações, ao deslocar o foco da cúpula política e diplomática ao tecido social brasileiro e otomano. Em suas próprias palavras: "um relacionamento mútuo que fugiu ao controle governamental" (p. 273).

De nossa parte, enumeramos algumas considerações críticas ao conteúdo do livro de Sochaczewski, bem como alguns acréscimos pontuais e eventualmente úteis para quem se interesse pelos temas abordados pela autora, lembrando que, por sua própria sugestão, "vale ainda reforçar a empiria e adentrar em detalhes" (p. 278):

1) Seria oportuno um aprofundamento conceitual quanto à qualificação dos dois impérios assinalados como "periféricos". Caberia questionar se os dois impérios "periféricos" em questão não estariam a caminho de se tornarem "semiperiféricos" (de acordo com a teoria do sistema-mundo de Immanuel Wallerstein, citado apenas de relance pela autora), em razão de seu peso geopolítico e geoeconômico regional;

2) Outro aspecto interessante de potencial aproximação entre os dois impérios, não abordado pela autora, diz respeito ao convite por carta enviado a D. Pedro I em abril de 1822, feito por nacionalistas "filo-helenistas", para que ele assumisse o trono da Grécia e liderasse os beligerantes gregos contra o Império Otomano. Um deles, o capitão Nikolaou Kiefala, chegou mesmo a comparar o então príncipe regente português ao fundador de Constantinopla, o imperador Constantino. A carta, no entanto, só chegou ao Rio de Janeiro após a independência do Brasil. Mais uma vez, o contraste fundamental entre os dois impérios (no caso, ainda o português) dizia respeito à disputa entre as duas grandes religiões monoteístas;

3) Em relação à segunda metade do século XIX, seria oportuno contrastar o movimento constitucionalista do escritor Namık Kemal, líder do movimento dos "Jovens Otomanos" (a não serem confundidos como os "Jovens Turcos") e fundador do jornal Hürriyet (A Liberdade), com movimentos políticos brasileiros da mesma época, como a Liga Progressista de 1864 e o Partido Republicano de 1873. 